\title{
Effect of letter orientation and sequential redundancy on the speed of letter search
}

\author{
SETH N. GREENBERG \\ Union College, Schenectady, New York 12308 \\ and \\ LESTER E. KRUEGER \\ Ohio State University, Columbus, Ohio 43210
}

\begin{abstract}
Subjects searched for target letters through upright or inverted sentences, words, and nonwords. Letters were easier to detect in sentences (vs. words) and words (vs. nonwords) under less demanding search conditions (e.g., one or two target lettere in memory set, upright presentation). Familiar letter orientation aided search under all conditions and its aid did not vary with memory set size (intercept effect only). The latter result, taken together with previous findings, indicates a general familiarity effect at the encoding stage. An analysis of facilitative and disruptive sequential redundancy effects indicated that facilitation depends on several key factors and, most important, on having words presented in uppercase.
\end{abstract}

How does familiarity affect perception? This question has engaged researchers for nearly a century (Cattell, 1886). A commonly held principle is that familiar visual patterns are easier to see than unfamiliar ones (Appelman \& Mayzner, 1981). However, as Egeth and Blecker (1971) noted, there may be "several kinds of familiarities each having a distinguishable effect on perception" (p. 325), and this makes it difficult to generalize results found with one kind of stimulus to another. Indeed, Appelman and Mayzner recently questioned whether familiarity generally aides perception, since no effect has been convincingly demonstrated with some kinds of stimuli. One problem with some past research has been the failure to isolate the familiarity effect at the encoding (input) stage, and thus to establish its perceptual nature. In some cases, familiarity may have aided storage and/or output coding (reporting/comparison) rather than input coding (feature extraction/interpretation) (see Krueger, 1975). The present study attempted to replicate the perceptual (encoding) effect of sequential redundancy found by Krueger (1970a) and to determine whether familiar letter orientation also aides encoding, which some have doubted (Appelman \& Mayzner, 1981; Krueger, 1975; Regan, 1981).

The present study used a variation of the lettersearch task (Krueger, 1970a). This task minimized the

The authors are grateful to Ronald G. Shapiro for useful discussions and programming assistance, and to three anonymous reviewers for their helpful comments. Requests for reprints should be sent to Seth N. Greenberg, Department of Psychology, Union College, Schenectady, New York 12308, or to Lester E. Krueger, Human Performance Center, 404-B W. 17th Avenue, Columbus, Ohio 43210 . role of the storage process, so any familiarity effects found can be attributed to encoding (input coding) or comparison processes (Krueger, 1975). The number of target letters searched for (memory set size) was varied in the present study in order to decide between these two processes. The more target letters searched for, the more memory comparisons that must be made for a given display (Sternberg, 1967, 1969). If familiarity aids memory comparison, then search time should increase less rapidly for familiar strings than for unfamiliar strings as memory set size increases (slope effect). If familiarity aids encoding or some other noncomparison stage instead, however, then its effect should remain constant as memory set size increases (intercept effect). While other noncomparison processes, such as response selection, may be involved, it will be assumed, following Krueger (1970a, 1982), that an intercept effect primarily reflects changes at the encoding stage.

The regular letter-search task was modified in the present case (1) to require subjects to respond to each item (word or nonword) in a multiitem display and (2) to permit variation in the number of items shown at one time. We required a response to each word or nonword not only to allow more data to be collected, but also to better reveal the effects of familiarity through the display. In previous studies, by contrast, only the total time needed to locate a target letter in an entire display (e.g., Krueger, 1970a) or to finish processing of an entire display (e.g., Healy, 1976) was measured. Comparing response times on target-present and targetabsent items would reveal whether letter search selfterminates as soon as the target letter is found (Krueger \& Shapiro, 1980), and whether that is the case for unfamiliar as well as for familiar items. 
Varying the number of items displayed permits a distinction to be made between familiarity effects based on peripheral information and those based on foveal information. If familiarity is more important in the processing of less distinct visual information (e.g., Massaro, 1975), then its effects should be magnified when peripheral information is available (preview condition). In addition, preview should lead to faster search. Rayner (1978), using an eye movement-contingent display, found that if a word was shown parafoveally on one fixation, it was named faster when it appeared foveally on the next fixation. With preview, the present task closely approximates a reading task, and so, conclusions reached here may generalize to reading as well (see Schindler, 1978).

In the present study, graphic, orthographic, and lexical-syntactic familiarity were manipulated in rough correspondence to the three main levels of processing units available to a reader: letters, words, and phrases (Drewnowski \& Healy, 1977). Accordingly, the present familiarity effects will be referred to as the letter orientation, intraword redundancy, and interword redundancy effects. Letter orientation was manipulated by presenting letters in a familiar upright orientation or rotated $180 \mathrm{deg}$ (up-down, left-right reversal). The effect of letter orientation, which has received surprisingly little attention in the literature, might be quite small, because of the presence of orientationally invariant distinctive features (Cooper \& Shepard, 1973). However, Egeth and Blecker (1971) found that upright orientation aided visual comparison. They pointed out, though, that "the comparison method is only one way, and a fairly restrictive one at that, of studying perception" (p. 321). Reicher, Snyder, and Richards (1976) found that two types of letter familiarity (upright vs. inverted; English vs. Gibson figures) affected speed and accuracy of letter search. Appelman and Mayzner (1981) said that studies finding familiarity effects at the letter level involved visual comparisons, whereas those finding no familiarity effects required identification. They concluded that familiarity effects at the letter level reflect comparison and not perceptual encoding processes. As noted above, the present study, employing Sternberg's $(1967,1969)$ additive-factors method, provides a more precise test as to which of these two operations is involved.

Familiarity at the letter level should affect the utilization of familiarity at higher levels. If the letters themselves are not recognizable, a reader may be unable to take advantage of his or her knowledge of sequential redundancy. However, numerous studies suggest that readers can process information from right to left (e.g., Kolers \& Perkins, 1969; Taylor, 1972), and Krueger (1976) found that intraword redundancy could be utilized when scanning mirror-reversed items from right to left. Thus, familiarity of higher level units appears to depend not upon the simple visual familiarity of their lower level constituents, but on familiarity of a more abstract nature.

The effect of intraword familiarity has been repeatedly demonstrated when one nonword or word is presented at a time (e.g., Carr, Lehmkuhle, Kottas, Astor-Stetson, \& Arnold, 1976; Krueger, 1970b;Reicher, 1969;Wheeler, 1970). Both reaction time (RT) (Krueger, 1970b) and error data (Carr et al., 1976) indicate that in this case words (vs. nonwords) reveal rather than conceal their component letters (but see Lawry, 1980).

Less successful, though, have been attempts to demonstrate a similar familiarity effect with displays containing several nonwords or words. Krueger (1970a) found faster letter search through sentences than through scrambled prose, as well as through words than through nonwords, but more recently, Drewnowski and Healy (1977), Healy (1976, 1980), and Schindler (1978) found that target letters were less readily detected when embedded in a set of sequentially redundant items. In light of these conflicting results, a new look at the intraword redundancy effect in multiitem search seemed warranted. Unlike Krueger's (1970a) multiitem search task, the present task measured the familiarity effect separately on target-present and target-absent items. Krueger's multiitem displays contained at most a single target-present item, so RT primarily reflected search through target-absent items, whereas the present task involved more frequent target detection and more closely resembled Healy's task. As in Healy's studies, target letters were present in half of the items.

An unresolved question is to what extent the word familiarity effect represents merely a shift in a speedaccuracy tradeoff. Healy (1976) found that letter search was faster, but less accurate, through familiar than through unfamiliar items, which suggests that accuracy was traded for speed. Healy focused on the pattern of errors within a given message in order to partial out this tradeoff, but it is still possible that within a passage the error-prone words (e.g., familiar nouns) are read faster than the less errorful words. Krueger and Weiss (1976) also obtained evidence for a speed-accuracy tradeoff in mutilated letter search (i.e., subjects were faster, but less accurate, on word than on nonword lists), but Krueger (1970a) found that the faster search through familiar items in regular letter search was not obtained at the expense of higher errors. A search for a single letter in a display, though, might not be the best way to monitor a speed-accuracy tradeoff. In the present study, subjects were free to trade speed for accuracy, and shifts in the tradeoff could be charted more precisely, since every word or nonword required a response.

Finally, the multiitem search task provided the opportunity to study the effect of interword redundancy (i.e., words in sentences compared to words in random sequences). McNeill and Lindig (1973) postulated that the further removed the processing level is from the target level, the less useful its information is 
to target detection. Consequently, the interword redundancy effect should be the weakest of the three familiarity effects. Sentences have been found to aid (Krueger, 1970a), provide no benefit to (Krueger, Keen, \& Rublevich, 1974), or disrupt (Drewnowski \& Healy, 1977) letter search.

In summary, the present experiment involved a comprehensive examination of the use of familiarity by the mature reader. It examined familiarity effects that have received scant attention or have yielded conflicting results. We hoped that the findings would shed further light on the generality of familiarity effects in perception.

\section{METHOD}

\begin{abstract}
Apparatus
Displays were presented at $32 \mathrm{~cd} / \mathrm{m}^{2}$ intensity on an Imlac PDS-4 graphics computer, whose cathode-ray tube had a greenishtint, fast-decay P31 phosphor (decay to $1 \%$ intensity at $.25 \mathrm{msec}$ after display offset). Stimulus letters, presented as thin, illuminated lines on a dark screen, were software generated, using short line vectors, so as to resemble normal English uppercase let ters. Subjects sat $70 \mathrm{~cm}$ from the display, with the head held fast in a chin rest.
\end{abstract}

\section{Stimulus Materials}

Each display contained a single horizontal row of six words or nonwords of five different letters each. Each letter was $.29 \mathrm{~cm}$ wide and $.43 \mathrm{~cm}$ high. Adjacent letters within an item were separated by $.19 \mathrm{~cm}$, and adjacent items were separated by $.67 \mathrm{~cm}$. The horizontal extent of each word or nonword was $2.21 \mathrm{~cm}(1.80 \mathrm{deg})$. When a subject fixated at the middle of one five-letter item, the following item began $1.77 \mathrm{~cm}(1.45 \mathrm{deg})$ to the left or right of fixation.

Three levels of sequential redundancy were used: sentences, words in scrambled order, and nonwords. Five different types of sentences were used. One type, for instance, had the word order: modifier, noun, verb, modifier, noun (e.g., PROUD SHOWY MODEL DATES SMART GUARD). Eight sentences of each type were formed, or 40 sentences in all. Since no word was used twice, 240 different words were presented. To produce 40 six-word nonsensical word groupings (scrambled word displays), the words in the sentences were randomly permuted within each of the six row positions. To form nonwords, letters were randomly permuted within each of the five letter positions within each of the six display positions (i.e., we randomly reassigned all letters in each display position to a different display but at the same position), with the constraint that no word be formed and that no nonword contain repeated letters. Four of the 40 six-item displays used at each level of redundancy were used for practice, and the remaining 36 were used for regular displays.

Three levels of preview were used. The subject saw no, one, or two upcoming words or nonwords in addition to the focal item. The current focal item was always extinguished immediately by the response. With preview set at 2 , for example, the subject first saw Items 1, 2, and 3. When the first response was made, Item 1 disappeared, and Items 2, 3, and 4 were presented. Items 2 and 3 kept the same positions on the screen in the two successive displays. Thus, the display marched ahead by one word or nonword each time a response was made.

Letter orientation was upright or inverted. In the inverted condition, the entire six-item display was rotated $180 \mathrm{deg}$ (up-down, left-right reversal), and the display began on the right and marched toward the left.
Memory set size was one, two, or three. Target letters were drawn from the set A, B, C, D, E, F, G, J, K, L, N, P, Q, R, T, $U, V$, and $Y$. Each letter's relative frequency of occurrence was kept constant across the three memory set sizes (e.g., 12\% of the one-, two-, and three-target sets contained an A). Further, each letter served as a target the same proportion of times in the sentence, scrambled-word, and nonword conditions (e.g., $12 \%$ of the targets appearing on sentence, scrambled-word, and nonword displays were A). A target letter was present in two, three, or four of the six five-letter items in a display, and the number of displays containing two, three, and four target-present strings was kept constant across the three levels of memory set size. Two complementary displays were devised for every combination of sequential redundancy, orientation, preview, and memory set size. When one display contained a target-absent item, the other display contained a target-present item. Thus if the second and fourth items contained targets in one display, then the complementary display had targets in the first, third, fifth, and sixth positions. Finally, the distribution of target letter appearances across the five within-item letter positions was approximately the same for the three levels of sequential redundancy.

The first item in each six-item display was considered practice and its data were not analyzed. All items in the first four displays at each level of sequential redundancy were also practice. With five regular items per display and 36 regular displays at each of three levels of sequential redundancy, there were 540 regular items or responses $(5 \times 36 \times 3=540)$. (Including practice items, there were $6 \times 40 \times 3=720$ items in all.) The 540 items represented all combinations of the following factors: row position of item $(2,3,4,5,6)$, sequential redundancy (sentences, scrambled words, nonwords), item type (target present, target absent), preview $(0,1,2)$, orientation (upright, left-to-right scan; inverted, right-to-left scan), and memory set size $(1,2,3)(5 \times 3 \times 2 \times 3 \times 2 \times 3=540)$.

\section{Procedure}

The subject pressed a footpedal to initiate each trial. The one, two, or three targets constituting the memory set were presented first for $6,1.8$, or $3 \mathrm{sec}$, respectively, either on the far left side of the screen (upright condition) or on the far right side (inverted condition), after which the first item or set of items (if there was preview) appeared. If the target set had appeared on the far left (right) side, the first item appeared just to its right (left); succeeding items, following each response, were displaced yet farther to the right (left).

Half of the subjects pressed a left-hand button to indicate "yes" (target present) and a right-hand button to indicate "no" (target absent), and the other half had the reverse hand assignment. Responses to each item were to be made as quickly as possible without sacrificing accuracy.

Each subject received the 120 six-item displays in three main blocks ( 40 sentences, 40 scrambled word displays, and 40 nonword displays), including the practice displays. Order of blocks was counterbalanced across subjects.

\section{Subjects}

Thirty Ohio State University and Ohio University undergraduates participated in order to receive credit for a psychology course. Data were excluded for six additional subjects whose error rates exceeded $10 \%$. All subjects had at least 20/30 vision (corrected), as tested with a Snellen chart.

\section{Data Analy sis}

All analyses of RT and error data were conducted using the analysis of variance. Preview 1 and 2 data were combined into a single preview (vs. no preview) condition, because a preliminary analysis found no difference between them. In addition, in the main analysis. data were collapsed over item position. Trials were excluded from the RT analysis if the subject made an error or if the RT was less than $75 \mathrm{msec}$ or more than $7.5 \mathrm{sec}$. 


\section{RESULTS}

Figures 1 and 2 show the main RT data, and the significance levels attained on the RT data are presented in Table 1. Responses were faster on target-present ("yes") than on target-absent ("no") strings, and when preview (vs. no preview) was available. Mean RT data increased linearly as memory set size increased, as is typical when subjects are not given extensive practice on a fixed target set (e.g., Briggs \& Blaha, 1969; Kaplan \& Carvellas, 1965; Sternberg, 1966). All of the above main effects were significant $(\mathrm{p}<.001$ in all cases; see Table 1).

The primary purpose of this study, though, was to investigate the effects of three levels of familiarity, whose main effects and interactions will be considered

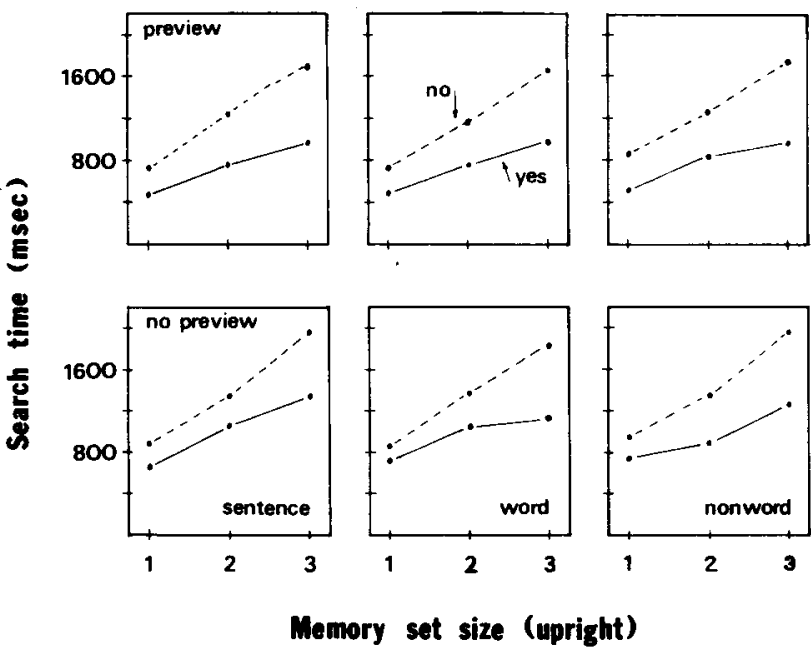

Figure 1. Mean response time in upright condition by preview vs. no preview, sequential redundancy, memory set size, and target presence (yes) vs. absence (no).

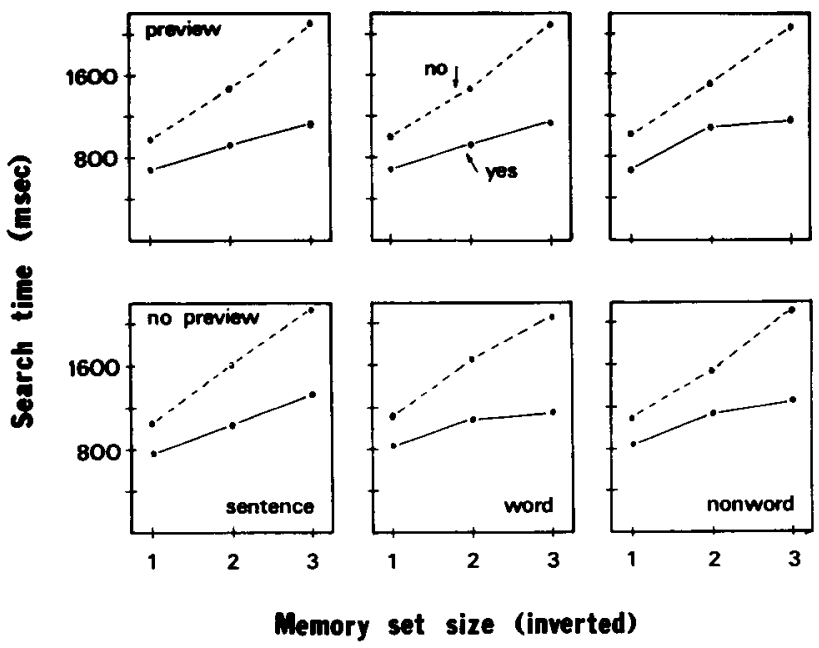

Figure 2. Mean response time in inverted condition by preview vs. no preview, sequential redundancy, memory set size, and target presence (yes) vs. absence (no).
Table 1

Analysis of Variance of Response Time (Main Analysis)

\begin{tabular}{|c|c|c|}
\hline Source & df & F Ratio \\
\hline Memory Set Size (M) & 2,48 & $401.91 \dagger$ \\
\hline Preview (P) & 1,24 & $118.87 \dagger$ \\
\hline Orientation $(\mathrm{O})$ & 1,24 & $130.93 \dagger$ \\
\hline Target Presence (T) & 1,24 & $173.50 \dagger$ \\
\hline Sequential Redundancy (R) & 2,48 & n.s.t† \\
\hline $\mathrm{M}$ by $\mathrm{P}$ & 2,48 & 2.76 \\
\hline $\mathrm{M}$ by $\mathrm{O}$ & 2,48 & n.s.t† \\
\hline $\mathrm{M}$ by $\mathrm{T}$ & 2,48 & $163.92 \dagger$ \\
\hline M by $\mathrm{R}$ & 4,96 & $4.30 * *$ \\
\hline $\mathrm{P}$ by $\mathrm{O}$ & 1,24 & $7.92 \dagger$ \\
\hline$P$ by $T$ & 1,24 & $8.74 \dagger$ \\
\hline $\mathrm{P}$ by $\mathrm{R}$ & 2,48 & $3.73^{*}$ \\
\hline $\mathrm{O}$ by $\mathrm{T}$ & 1,24 & $23.19 \dagger$ \\
\hline $\mathrm{O}$ by $\mathrm{R}$ & 2,48 & n.s.t \\
\hline $\mathrm{T}$ by $\mathrm{R}$ & 2,48 & n.s.t† \\
\hline $\mathrm{M}$ by $\mathrm{P}$ by $\mathrm{O}$ & 2,48 & $5.74 * *$ \\
\hline $\mathrm{M}$ by $\mathrm{P}$ by $\mathrm{T}$ & 2,48 & n.s. t $^{-1}$ \\
\hline$M$ by $P$ by $R$ & 4,96 & $6.94 \dagger$ \\
\hline $\mathrm{M}$ by $\mathrm{O}$ by $\mathrm{T}$ & 2,48 & $4.63^{*}$ \\
\hline $\mathrm{M}$ by $\mathrm{O}$ by $\mathrm{R}$ & 4,96 & 1.96 \\
\hline $\mathrm{M}$ by $\mathrm{T}$ by $\mathrm{R}$ & 4,96 & n.s. $\dagger \dagger$ \\
\hline$P$ by $O$ by $T$ & 1,24 & 2.17 \\
\hline$P$ by $O$ by $R$ & 2,48 & 1.55 \\
\hline $\mathrm{P}$ by $\mathrm{T}$ by $\mathrm{R}$ & 2,48 & n.s.†† \\
\hline $\mathrm{O}$ by $\mathrm{T}$ by $\mathrm{R}$ & 2,48 & n.s. $\dagger^{\dagger}$ \\
\hline $\mathrm{M}$ by $\mathrm{P}$ by $\mathrm{O}$ by $\mathrm{T}$ & 2,48 & n.s.t† \\
\hline$M$ by $P$ by $O$ by $R$ & 4,96 & n.s.t† \\
\hline$M$ by $O$ by $R$ by $T$ & 4,96 & n.s.t† \\
\hline $\mathrm{M}$ by $\mathrm{P}$ by $\mathrm{T}$ by $\mathrm{R}$ & 4,96 & n.s.t \\
\hline $\mathrm{P}$ by $\mathrm{O}$ by $\mathrm{T}$ by $\mathrm{R}$ & 2,48 & n.s.t† \\
\hline $\mathrm{M}$ by $\mathrm{P}$ by $\mathrm{O}$ by $\mathrm{T}$ by $\mathrm{R}$ & 4,96 & n.s.t† \\
\hline
\end{tabular}

${ }^{*} p<.05 . \quad{ }^{* *} p<.01 . \quad \dagger p<.001 . \quad \quad \dagger F<1$.

in the following two sections: letter orientation effect and sequential redundancy (intraword and interword effects).

\section{Letter Orientation Effect}

Upright orientation facilitated search significantly $(\mathrm{p}<.001)$. The time savings for upright (vs. inverted) items was over $150 \mathrm{msec}$. Further, the upright advantage held under all levels of the various factors studied (see Figures 1 and 2), and it remained nearly constant across memory set size, as Figure 3 shows. According to Sternberg (1967, 1969), if a factor affects memory comparison, then it should interact with memory set size (slope effect), but if it affects only encoding, then its effect should remain constant (intercept effect). Thus, the present results indicate that letter orientation affects only encoding. The upright advantage was greater with preview than with no preview $(\mathrm{p}<.01)$, and a significant Orientation by Preview by Memory Set Size interaction $(p<.01)$ provided the only indication of a comparison effect: With upright stimuli, preview aided memory comparison as well as encoding (see Figure 1).

\section{Sequential Redundancy (Intraword and} Interword Effects)

Three levels of sequential redundancy were used: 
nonwords, words, and sentences. An intraword effect refers to an RT difference between words and nonwords; an interword effect refers to an RT difference between sentences and words. Sequential redundancy had no significant main effect $(p>10)$, but it did interact significantly with memory set size $(\mathrm{p}<.01)$, preview $(\mathrm{p}<.05)$, and both factors $(\mathrm{p}<.001)$ (see Table 1 and Figure 4). Sequential redundancy generally aided search if preview was permitted and there were only one or two targets in the memory set (see Figure 4). If preview was not allowed and there were three targets, then interword redundancy inhibited search. Newman-Keuls tests here showed that words in sentences were judged significantly more slowly than scrambled words by $179 \mathrm{msec}$

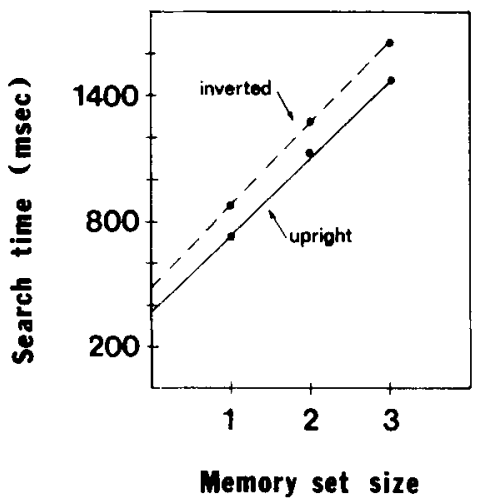

Figure 3. Mean response time of upright vs. inverted items by memory set size.

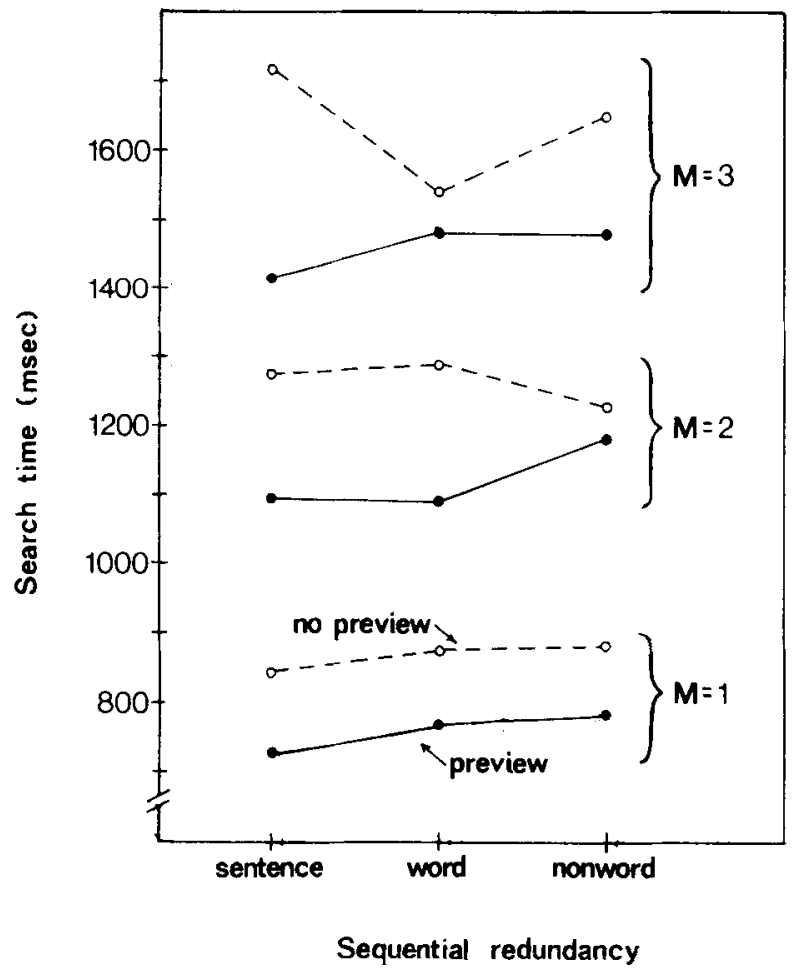

Figure 4. Mean response time by preview vs. no preview, sequential redundancy, and memory set size (M).
Table 2

Separate Analyses of Variance of Response Time for Upright and Inverted Letter Strings

\begin{tabular}{|c|c|c|c|}
\hline \multirow[b]{2}{*}{ Source } & \multirow[b]{2}{*}{ df } & \multicolumn{2}{|c|}{ F Ratio } \\
\hline & & Upright & Inverted \\
\hline Memory Set Size $(\mathrm{M})$ & 2,48 & $289.05 \dagger$ & $415.80 \dagger$ \\
\hline Preview (P) & 1,24 & $123.69 \dagger$ & $36.40 \dagger$ \\
\hline Target Presence (T) & 1,24 & $192.37 \dagger$ & $143.90 \dagger$ \\
\hline Sequential Redundancy (R) & 2,48 & 1.15 & n.s. $\dagger^{-}$ \\
\hline $\mathrm{M}$ by $\mathrm{P}$ & 2,48 & $7.96 * *$ & 1.16 \\
\hline $\mathrm{M}$ by $\mathrm{T}$ & 2,48 & $99.60 \dagger$ & $128.60 \dagger$ \\
\hline M by $R$ & 4,96 & $4.27 * *$ & 2.57 \\
\hline $\mathrm{P}$ by $\mathrm{T}$ & 1,24 & $7.87 * *$ & 1.72 \\
\hline $\mathrm{P}$ by $\mathrm{R}$ & 2,48 & $6.48 * *$ & n.s. $\dagger^{\dagger}$ \\
\hline $\mathrm{T}$ by $\mathrm{R}$ & 2,48 & 2.22 & n.s. $\dagger^{\dagger}$ \\
\hline $\mathrm{M}$ by $\mathrm{P}$ by $\mathrm{T}$ & 2,48 & n.s. t† $^{-}$ & n.s.t† \\
\hline $\mathrm{M}$ by $\mathrm{P}$ by $\mathrm{R}$ & 4,96 & $3.43 *$ & $4.43 \dagger$ \\
\hline $\mathrm{M}$ by $\mathrm{T}$ by $\mathrm{R}$ & 4,96 & n.s. $\dagger_{\dagger}$ & n.s.t† \\
\hline $\mathrm{P}$ by $\mathrm{T}$ by $\mathrm{R}$ & 2,48 & n.s. †† $^{-}$ & n.s.t† \\
\hline $\mathrm{M}$ by $\mathrm{P}$ by $\mathrm{T}$ by $\mathrm{R}$ & 4,96 & n.s. $\dagger \dagger$ & n.s.†† \\
\hline
\end{tabular}

$(p<.01)$ and nonwords by $69 \mathrm{msec}(p<.05)$. With preview, the sentence condition produced the smallest RT, whereas with no preview, it produced the largest mean RT. The only significant intraword redundancy effect was a word advantage in the preview, two-target condition $(\mathrm{p}<.05)$.

Sequential redundancy did not interact with orientation $(\mathrm{p}>.10)$, but because most studies investigating it have employed only upright stimuli, RT data in the upright condition were analyzed separately. To complement this analysis, RT data in the inverted condition also were examined separately, and they will be discussed after those in the upright condition. As Table 2 shows, the upright condition generally produced more highly significant results than the inverted condition.

Upright condition. A comparison of Tables 1 and 2 (upright condition) reveals that the upright data (Figure 1) showed all of the significant main effects and interactions obtained in the main analysis, except, of course, those involving orientation. Of primary interest, though, were the facilitative effects involving sequential redundancy that appeared in various conditions. Search through sentences produced time savings (compared to nonwords) of $86 \mathrm{msec}$ in the one-target condition $(\mathrm{p}<.025)$ and $71 \mathrm{msec}$ in the preview condition $(\mathrm{p}<.01)$. In the main analysis, the corresponding time savings were 46 and $42 \mathrm{msec}$, respectively $(p>.10$ in both cases). A word (vs. nonword) advantage of $55 \mathrm{msec}$ in the preview condition was significant $(p<.05)$. With one target and preview, sequential redundancy showed a time savings of $111 \mathrm{msec}(\mathrm{p}<.01)$, consisting of a sentence (vs. word) advantage of $60 \mathrm{msec}$ $(p<.05)$ and a nonsignificant word (vs. nonword) advantage of $41 \mathrm{msec}(p>.10)$. Even though it is not quite significant, the word advantage here considerably exceeds that found in the main analysis $(11 \mathrm{msec})$. In summary, under more traditional and perhaps some- 
what less demanding testing conditions, intraword and interword effects were evident.

A further analysis of upright data examined the effect of sequential redundancy by row position. As Figure 5 indicates, RT was consistently higher on nonwords $(p<.05$ or better at each row position at both levels of preview). While preview had little impact on the intraword redundancy effect, it did enhance the inter. word redundancy effect significantly $(p<.05)$, as a comparison of Figures $5 \mathrm{a}$ and $5 \mathrm{~b}$ shows.

Inverted condition. As Table 2 (inverted condition) shows, significant effects on RT of target presence, memory set size, and preview were obtained with inverted stimuli (see Figure 2). All of these effects resembled those obtained in the main and upright analyses. However, the positive effects of sequential redundancy were much weaker here than with upright stimuli. For example, with preview, the word (vs. nonword) advantage was $55 \mathrm{msec}$ with upright items, but only $6 \mathrm{msec}$ with inverted items. With one target, the sentence (vs. nonword) advantage was $75 \mathrm{msec}$ in the upright condition, but only $14 \mathrm{msec}$ in the inverted condition. In fact, only in the two-target, preview case was the sequential redundancy advantage as great on

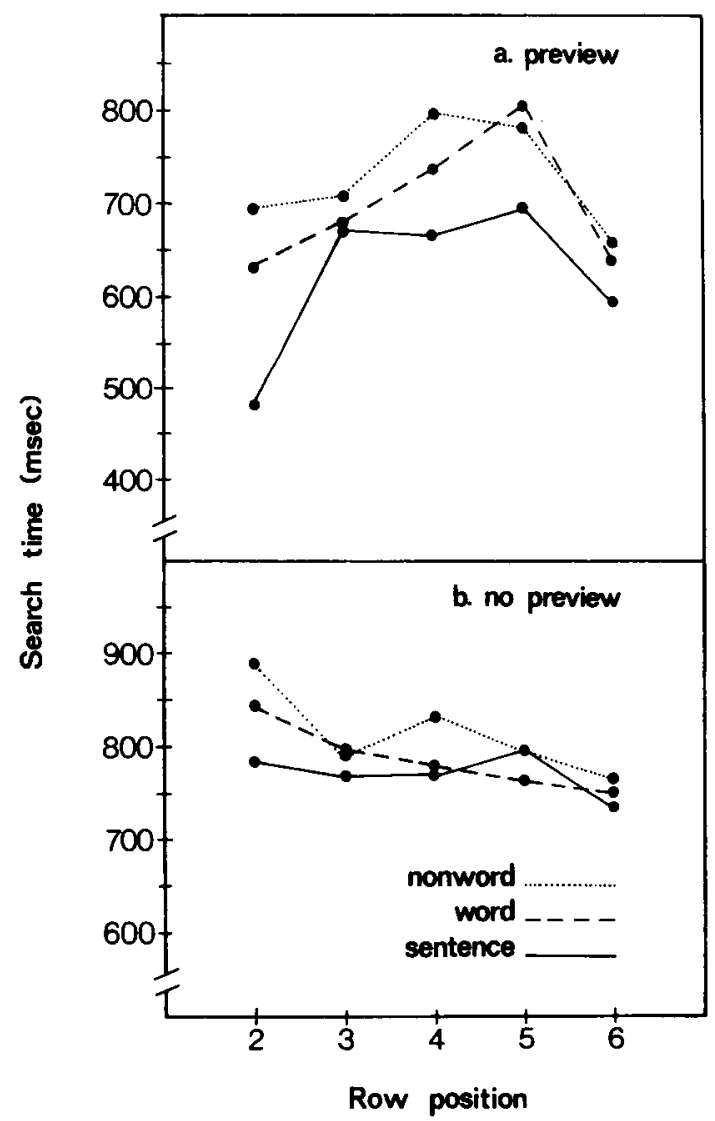

Figure 5. Mean response time for preview and no-preview conditions showing sequential redundancy by row position of item. Item 1 was considered practice and was not included. inverted items as on upright items. The disruptive effect of sentences in the no-preview condition was evident in the inverted case, but it was smaller than in the upright case.

\section{Self-Terminating Search Model}

Finally, the RT data were fitted to a serial, selfterminating search model (based on Krueger \& Shapiro, 1980), according to which the subject scans each item letter by letter and self-terminates with a "yes" response as soon as a target is detected. The target letter appeared almost equally often in each of the five within-item serial positions, so subjects should have responded "yes" after searching an average of three letters. On "no" (target-absent) trials, on the other hand, all five letters must be scanned, plus an additional display letter or two, due to occasional rechecking, as some have claimed (e.g., Briggs \& Blaha, 1969). To fit the RT data, a grid search determined the estimated parameter values that minimized the sum of squared deviations between predicted and observed RT.

The parameters estimated in this study were: (1) base time (intercept value), (2) comparison time per memory letter per display letter tested (slope value), and (3) number of display letters rechecked on "no" trials. Base time includes encoding time for the item as a whole, as well as the time needed for response selection, response execution, and so on. Comparison time (i.e., the time needed to compare a given display letter with a target letter in memory) was assumed to be the same whether the display letter matched the target letter or not. With one, two, and three targets in the memory set, a mean of 3,6 , and 9 comparisons, respectively, were made on "yes" trials, and 5,10, and 15, respectively, on "no" trials. It should be noted that although visual search was assumed to be self-terminating, memory search was assumed to be exhaustive (Sternberg, 1966). That is, if a display letter was tested at all, it was compared against all memory letters. Krueger and Shapiro (1980), relying on the same assumptions, satisfactorily fitted data on search for presence and search for absence.

The model was fitted separately for the upright and inverted displays, as well as to the overall data. As Figure 6 shows, the predicted RT functions (lines) provided a reasonable fit to the observed data (dots) in both cases. As Table 3 indicates, the estimated comparison time per memory letter per display letter tested was 93 msec. Kristofferson, Groen, and Kristofferson (1973) and Krueger and Shapiro (1980) also found scan times per letter of approximately the same duration. The subjects needed $438 \mathrm{msec}$ for other, base-time processes, which is in the range of values reported by Krueger and Shapiro and is very similar to the $440-\mathrm{msec}$ value reported by Kaplan and Carvellas (1965). Thus the data are consistent with previous studies and demonstrate that the same self-terminating search process was used when letters were inverted as when they were upright. 


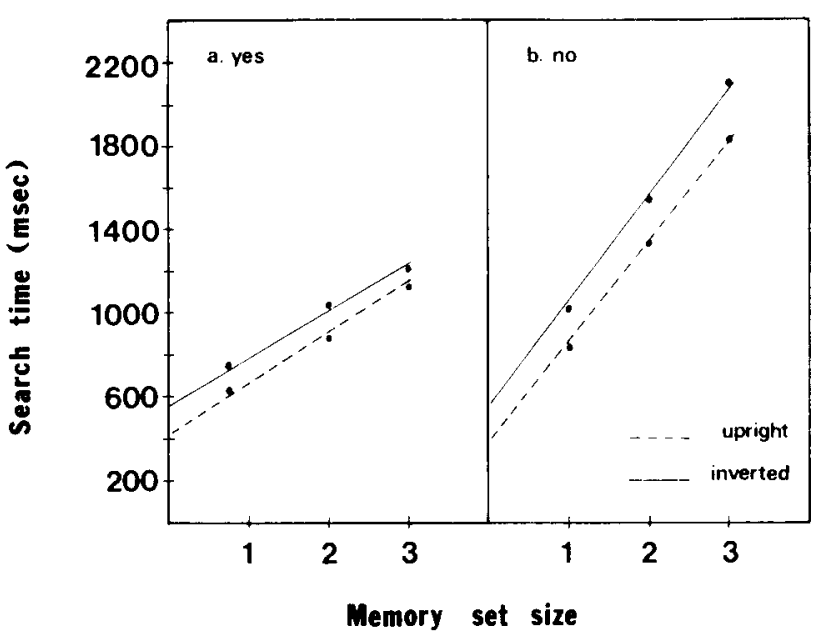

Figure 6. Mean response times by orientation, target presence (yes) vs. absence (no), and memory set size. The lines show the predictions of the serial, self-terminating model. The dots are observed mean response times.

Table 3

Estimated Parameter Values for Serial, Self-Terminating Model

\begin{tabular}{lccc}
\hline Condition & $\begin{array}{c}\text { Base } \\
\text { Time }\end{array}$ & $\begin{array}{c}\text { Comparison } \\
\text { Time per } \\
\text { Letter }\end{array}$ & $\begin{array}{c}\text { Mean Number } \\
\text { of Letters } \\
\text { Rechecked* }\end{array}$ \\
\hline Upright & 363 & 86 & .6 \\
Inverted & 515 & 97 & 1.6 \\
All & 438 & 93 & 1.1 \\
\hline
\end{tabular}

Note-Times are given in milliseconds. *No" trials only.

Table 4

Mean Percentage Error Rate by Sequential Redundancy, Orientation, Preview, Memory Set Size, and

Target Present vs. Absent

\begin{tabular}{|c|c|c|c|c|c|c|}
\hline \multirow{2}{*}{$\begin{array}{c}\text { Target } \\
\text { Set Size }\end{array}$} & \multicolumn{3}{|c|}{ Target Present } & \multicolumn{3}{|c|}{ Target Absent } \\
\hline & $S$ & W & NW & $S$ & W & NW \\
\hline \multicolumn{7}{|c|}{ Upright, Preview } \\
\hline 1 & 1.0 & 1.6 & .3 & .6 & 4.0 & 1.0 \\
\hline 2 & 6.3 & 7.0 & 5.6 & 1.6 & 5.3 & 3.3 \\
\hline 3 & 10.6 & 16.6 & 10.6 & 2.3 & 4.6 & 2.0 \\
\hline \multicolumn{7}{|c|}{ Upright, No Preview } \\
\hline 1 & .3 & 2.0 & 1.3 & .6 & 2.6 & 6 \\
\hline 2 & 5.3 & 7.3 & 4.0 & .6 & .6 & 2.0 \\
\hline 3 & 14.0 & 6.6 & 16.6 & 2.6 & .6 & 4.6 \\
\hline \multicolumn{7}{|c|}{ Inverted, Preview } \\
\hline 1 & .3 & .6 & 2.3 & 1.0 & 4.0 & 1.0 \\
\hline 2 & 7.6 & 6.0 & 7.6 & 6.0 & 2.6 & 2.3 \\
\hline 3 & 10.8 & 1.6 & 13.3 & 1.0 & 2.3 & 3.6 \\
\hline \multicolumn{7}{|c|}{ Inverted, No Preview } \\
\hline 1 & 2.6 & 2.6 & 1.3 & 2.0 & 1.3 & 2.0 \\
\hline 2 & 9.3 & 8.0 & 3.3 & .0 & 2.0 & 1.3 \\
\hline 3 & 8.6 & 9.3 & 12.0 & 4.6 & 2.0 & 2.6 \\
\hline
\end{tabular}

Note $-S=$ sentences, $W=$ words, $N W=$ nonwords.

\section{Error Data}

The error data are shown in Table 4. Errors increased as memory set size increased $(p<.01)$, and misses on target-present trials outnumbered false alarms on targetabsent trials $(\mathrm{p}<.01)$, but no other main effects or interactions were significant on errors. Most important, though, was that errors for sentences $(4.2 \%)$, words $(4.5 \%)$, and nonwords $(4.4 \%)$ were virtually identical. This equality held even when the word advantage and sentence advantage on RT were strongest (i.e., upright, one-target condition) (see Table 4). Hence, the intraword and interword effects on RT cannot be dismissed as due simply to shifts on a speed-accuracy tradeoff. In addition, errors were nearly equal for the upright $(4.5 \%)$ and inverted conditions (4.4\%).

The elimination of error-prone subjects may have reduced the opportunity to detect a speed-accuracy tradeoff. However, the $10 \%$ criterion used to eliminate subjects was an overall error rate. Thus, sufficient opportunity existed for the inclusion of subjects who might have made $10 \%$ to $15 \%$ errors in the redundant or upright conditions and $0 \%$ to $5 \%$ in the nonword or inverted conditions.

\section{DISCUSSION}

\section{Letter Orientation Effect}

The letter orientation effect found here was large and robust, far surpassing both sequential redundancy effects. The present task involved letter detection, and it might be expected that the farther one gets from the letter level, the less useful or relevant is the information provided (McNeill \& Lindig, 1973) and thus the less facilitation its familiarity would provide, which is just what we found. More important, the present results pointed to encoding as the locus of the letter orientation effect. Appelman and Mayzner (1981) concluded from a review of the literature that there was no basis for positing that familiarity at the letter level affects perceptual encoding. Further, Regan (1981) said that the Familiarity by Trial Type (i.e., same vs. different) interaction typically obtained in the visual comparison task (e.g., Egeth \& Blecker, 1971; Hock, 1973; Regan 1981) suggested a comparison locus. This may be the case, but the interaction may instead reflect a passthrough of effects from an earlier (i.e., encoding) stage. If, as Regan said, unfamiliar items are compared serially, but familiar items holistically, this may well result from distinct coding strategies for familiar and unfamiliar items. The present study provides a more direct test of the locus, and the intercept effect obtained here clearly implicates the encoding stage.

Contrary evidence was reported by Ambler and Proctor (1976), who tested both English and Japanese letters using a memory search task and found that letter familiarity interacted with memory set size. However, as Regan noted, Ambler and Proctor's task may have involved memory rather than perception. It should be noted, too, that our finding of an encoding locus for the letter orientation effect is consistent with Krueger's (1970a, 1982) and Juola's (Note 1) localization of the intraword familiarity effect at encoding. 
Appelman and Mayzner (1981), in reviewing the literature, found no significant correlation between letter frequency and letter perceptibility when single letters had to be identified. This limits the generality of familiarity effects, they concluded. However, except for A and I, different letters are probably experienced about equally frequently as single units, so the letter identification task may not reveal how differential letter frequency in words affects letter perception there. In fact, adults who served as subjects might have had more prior experience with Xs and Ys than other letters as independent units. Moreover, differences in shape and featural content may make some letters much easier to identify or detect, thus overriding any effect of letter frequency. The present procedure, in which the same letter shapes were presented upright or inverted, largely removes the featural factor and thus provides a better indication of how letter familiarity influences letter perception.

\section{Sequential Redundancy Effects}

The sequential redundancy effects found here were not as strong as those of Krueger (1970a). This may be due in part to the present procedure, which required an explicit, overt response to each word or nonword. Unlike previous research, too, the sequential redundancy effect was eliminated with unfamiliar orientation. Krueger (1976) and Well, Pollatsek, and Schindler (1975) found that changes in orientation had no substantial effect on the word advantage. However, Well et al. had subjects compare adjacent strings, which may have lessened the impact of variations in orientation. Krueger (1976) used a letter search task, but his letters were only mirror reversed, not rotated by $180 \mathrm{deg}$, and he showed only one or two items per display. Our more reading-like task, which required extensive eye movements and rapid analysis of successive items, may have left too little capacity or time to discern the high-order sequential relationships present on inverted strings.

The finding of intraword and interword facilitation effects under traditional test conditions is consistent with previous work (e.g., Krueger, 1970a). The interword effect was relatively weak, and it was more vulnerable to disruption from increased processing demands. Without a precise measure of interword redundancy (e.g., via a cloze procedure), we must be cautious in generalizing about the interword effect from the present results. However, since Krueger (1970a) also found a relatively weak interword effect using well constructed sentences from Readers's Digest, it seems safe to conclude that this level of familiarity normally is less useful than others. More difficult to explain is the disruptive effect of interword redundancy in the no-preview condition. Perhaps inappropriate predictions generated by our more contrived or awkward sentences could be dispelled with preview of upcoming words.

Preview enhanced the facilitative effect of each of the three levels of familiarity tested (orientation, intraword redundancy, interword redundancy). This indicates that subjects can process peripheral information quite extensively before they have finished processing the foveal item. Similiarly, Fischler (1975) and Sternberg and Scarborough (Note 2) obtained evidence that several items in a rapid input series may be compared concurrently with a target set. Keele (1973, Chapter 5) concluded that several items may contact memory simultaneously without interfering with each other. Further, preview gives the subject greater control over the task. Assuming that the subject knows best how to allocate attention in a reading-like task, the more opportunity we provide to do so, the easier it should be for the subject to take advantage of any familiarity present.

Unfortunately, the locus of the sequential redundancy effects could not be determined, because increasing the memory set size eliminated the unitization of sequential redundancy. Krueger (1969) obtained a similar inhibiting effect of increased memory set size with unpracticed subjects, and he concluded that "the increased processing load in looking for two targets ... may preempt much of the processing capacity that normally aids the subject in encoding redundant items (cf. Moray, 1967)" (p. 107). He found no inhibiting effect, though, when he used highly practiced subjects (Krueger, 1969, 1970a) or a large display (Krueger, 1982).

None of the facilitative effects was obtained at the expense of increased errors. Drewnowski and Healy (1977) said that "when subjects are searching for targets at a given level, we should expect them to make more detection errors when they are able to identify units at a higher level than the level of the target" (p. 637). Specifically, more letter detection errors should occur in words than nonwords. In the present study, however, errors were equal across all three levels of sequential redundancy, and the $\mathrm{RT}$ data indicated that familiar strings aided rather than hindered detection of target letters, particularly under traditional test conditions. Clearly, the present results are at odds with Drewnowski and Healy's prediction, and with Healy's repeated finding (e.g., Healy, 1976, 1980) that familiar letter strings conceal their embedded letters.

To fully understand the sequential redundancy effect, we must account in a principled way for the fact that some studies find redundancy helpful in letter detection and others find it disruptive. Healy $(1976,1980)$ and Lawry (1980) hypothesized that familiarity with redundant strings leads to a unitization of the word so that it is processed without dependence on letter-by-letter analysis. Hence, letters in words may never get completely processed. Healy argued that unitization normally is automatic and faster than letter analysis, but she conceded that some test conditions that encourage slower controlled processes may allow letters to be identified before words are unitized. Presumably, under those conditions, sequential redundancy could help reveal letters. The next section considers procedural differences among the multiitem studies (summarized in Table 5) 
Table 5

Comparison of Procedures Used in Multiitem Letter-Detection Studies

\begin{tabular}{|c|c|c|c|c|c|c|c|}
\hline \multirow[b]{2}{*}{ Study } & \multicolumn{5}{|c|}{ Factor } & \multicolumn{2}{|c|}{ Familiarity Effects } \\
\hline & 1 & 2 & 3 & 4 & 5 & Intraw & \\
\hline Krueger $(1970 a)$ & + & 0 & + & + & + & + & + \\
\hline Krueger, Keen, \& Rublevich (1974) & + & 0 & + & + & + & + & 0 \\
\hline Present Study (traditional test conditions) & + & 0 & + & + & + & + & + \\
\hline Present Study (most difficult test conditions) & - & 0 & + & + & + & 0 & - \\
\hline Schindler $(1978$, with content words)* & + & 0 & 0 & + & - & & + \\
\hline Schindler $(1978 \text {, with function words })^{*}$ & + & 0 & 0 & - & - & - & - \\
\hline Drewnowski \& Healy (1977, Experiment 3) & - & - & - & - & + & 0 & \\
\hline Drewnowski \& Healy $(1977$, all but Experiment 3$)$ & $\ldots$ & - & -- & - & - & - & - \\
\hline Healy (1976, all but Experiment 4$)$ & - & - & - & - & - & - & \\
\hline Healy (1976, Experiment 4) & - & - & - & + & - & - & \\
\hline Healy ( 1980 , all but Experiment 3 ) & - & - & - & - & - & - & - \\
\hline Healy (1980, Experiment 3 ) & - & - & - & + & - & - & - \\
\hline
\end{tabular}

Note-Factor 1: easy (+) vs. difficult (-) tasks. Factor 2: vowel (+) vs. consonant (-) targets. Factor 3: search $(+)$ vs. read/search $(-)$ instructions. Factor 4: content (+) vs. function (-) words. Factor 5: uppercase (+) vs, lowercase (-) letters. A plus sign indicates a facilitative factor (columns 1-5) or effect (Columns 6 and 7), a minus sign indicates a disruptive factor or effect, a zero indicates that both a facilitative and a disruptive factor were present or no effect was found, and a blank indicates that the presence of a factor or effect could not be assessed or did not pertain. "Rechecking is assumed to compensate for other task demands and to make them easy.

that might affect or be affected by unitization and thus might help to predict when sequential redundancy would aid letter detection.

\section{Procedural Differences}

Five key factors (Columns 1-5, Table 5) seem to predict the direction of intraword and interword redundancy effects (Columns 6 and 7, Table 5). As Table 5 shows, the greater the number of positive factors or indicators associated with an experiment, the more likely its effect on letter detection will be facilitative. A Kendall's tau analysis found a strong positive correlation $(\mathrm{T}=.74, \mathrm{p}<.01)$ between the number of positive factors and the rankings of the familiarity effect (based on the sum of the signs of the intraword and interword redundancy effects). While the overall association was strong, some factors seemed more important than others. Each factor will now be discussed in turn.

Factor 1: Task difficulty. As task difficulty increased in the present study, the facilitative effect of sequential redundancy decreased, and the same trend was evident across other studies (see Table 5). In classifying studies as easy vs. difficult, the most important factor usually was the response mode. Having subjects encircle targets (e.g., Healy, 1976, 1980) was assumed to increase the processing load, because it requires greater manual dexterity than does pressing a button. The benefit available from sequential redundancy may be reduced in two different ways. First, increasing the task difficulty should leave less spare capacity to discern and utilize sequential redundancy. Second, if unitization generally requires less attention than letter detection (Healy, 1980), then increasing the task difficulty may disrupt letter detection more than unitization.

Factor 2: Vowel vs. consonant targets. As Table 5 shows, the facilitative effect typically is eliminated when no vowels are used as targets. Drewnowski and Healy (1977) and Healy $(1976,1980)$ used only consonants as targets, principally the letter " $t$," and found only disruption, whereas the other multiitem search studies used vowels and consonants and often found facilitation (see Table 5)

Search for vowel targets typically is faster than search for consonant targets (e.g., James, 1974; James \& Smith, 1970; Mason, Note 3), but James and Smith found no vowel advantage when nonwords were tested. Vowel search may be faster than consonant search in words because "the amount of stimulus information necessary for a correct judgment is less with vowel probes than with consonant probes, since there are fewer alternatives to confuse with the correct letter" (James \& Smith, 1970, p. 59). Further, Mason found that sequential redundancy did not help search for consonants on either target-present or target-absent (catch) trials, whereas sequential redundancy on at least the trigram level aided vowel detection on target-present trials. Only single-letter spatial redundancy appeared to affect the search for consonants.

The exclusive use of consonant targets by Healy $(1976,1980)$ thus may have further reduced the likelihood that intraword familiarity would aid letter detection. Schindler (1978) found disruption even though he used both vowels and consonants, but this may be because he used lowercase letters and compared function words with content words.

Factor 3: Search vs. read/search. In comparing her study to that of Krueger (1970a), Healy (1976) noted that a potentially important difference was in the instructions. She had subjects "read" and search, whereas Krueger, like us, had subjects only search. Healy said that when reading is stressed, subjects will employ the largest unit available to them, which in her case was 
"larger than letters in the prose passage, but not in the scrambled-letter passage" (Healy, 1976, p. 237). Healy thus may have found a disruptive effect because her instructions, unlike ours, emphasized unitization. However, Schindler (1978) found no significant difference $(p>.20)$ between read-and-search and searchonly instructions. He concluded that reading is an involuntary, conditioned response to the familiar visual features of printed English, that is, "paragraph format, punctuation, capitalization" (Schindler, p. 128). Of course, if such props were missing, then perhaps reading and unitization would be less automatic. Krueger's (1970a) displays, like ours, deviated somewhat from traditional English prose format (i.e., no punctuation marks were used and all letters were uppercase), and this may have helped subjects to adhere to the search-only instructions.

Factor 4: Content vs. function words. Schindler (1978) studied the function/content word distinction at the interword level. Having a coherent prose context increased the accuracy of letter detection in content words but decreased that in function words. This finding helps to explain earlier results, since, as Schindler noted, Krueger (1970a) found a sentence advantage using primarily content words as target-bearing words (19 of 24), whereas Healy's (1976) sentence disadvantage was found in function words. Almost all of the target-bearing words in the present study were content words, so our facilitative effects fit Schindler's prediction.

Function words are among the most frequently occurring words in English. A nonmonotonic relationship thus may exist between item frequency and the ease of letter detection. As items progress from the lowfrequency nonword or rare word level to a moderatefrequency level, intraword redundancy becomes stronger and consequently more useful to letter detection. Beyond the moderate-frequency level, though, unitization may be so rapid, and the word gestalt so strong, that letters are immediately overwhelmed and concealed by the high-frequency word. Haber and Schindler's (1981) data fit this prediction; detection errors were more pronounced in function words and infrequent content words than in frequent content words.

While the function/content word distinction or frequency factor accounts for several of the findings listed in Table 5, there are results it alone cannot explain. Specifically, Healy $(1976,1980)$ found that rare words revealed their letters better than common words (in random prose), whereas Krueger (1970a) found the opposite effect.

Factor 5: Uppercase vs. lowercase. This is probably the most important factor of all. Haber and Schindler (1981) found that misprints that preserved the shape of function and high-frequency content words were more difficult to detect than those that changed the shape. They concluded that a familiar item "described by its visual pattern of ascenders, descenders and small letters when printed in lowercase type" (Haber \&
Schindler, 1981 , p. 578), is processed as a unit (unitization) because of its familiar visual shape. Global features may dominate the processing of familiar patterns rendering local letter information less salient (Lawry, 1980). However, familiar visual patterns may be discernible only when lowercase type is used. Words in uppercase appear less frequently in print and are much more uniform in shape, so global features probably are unimportant in their processing. When unitization is discouraged, a reader may attend to local features and thus utilize sequential redundancy in letter detection. For this reason, component letters should be hidden by familiar words in lowercase but revealed by familiar words in uppcase. Table 5 shows that, indeed, all of the multiitem studies using uppercase found facilitative effects, whereas all but one of those using lowercase found disruptive effects.

Similarly, Mason (Not 3) found faster search through words than nonwords when uppercase was used, but not when lowercase was used. Drewnowski and Healy (1977) found fewer detection errors, especially on function words, when every other word or every other letter was in uppercase than when lowercase letters alone were used. Thus, "when the processing of units at levels higher than the letter is impeded, the percentages of letter detection errors on the word the are reduced to near chance level" (Drewnowski \& Healy, 1977 , p. 641). This is strong evidence that case manipulation can affect the unitization of even the most familiar items. Thus, when global processing draws attention away from a word's letter components, it is because of the word's familiar visual shape, not its familiar spelling patterns (sequential redundancy), that the target letter is concealed.

\section{Conclusions}

In summary, the present results indicate that both letter orientation and sequential redundancy aid letter search, although the latter effect is less robust. Furthermore, the present results, together with those of Krueger (1970a, 1982) and Juola (Note 1), indicate that the locus of both effects is at encoding.

\section{REFERENCE NOTES}

1. Juola, J. F. Visual search through sequentially presented letter strings. Paper presented at the meeting of the Midwestern Psychological Association, Chicago, May 1979.

2. Sternberg, S., \& Scarborough, D. L. Parallel testing of stimuli in visual search. Paper presented at the International Symposium on Visual Information Processing and Control of Motor Activity, Sofia, Bulgaria, July 1979.

3. Mason, M. Letter search time as a function of spatial and sequential redundancy. Paper presented at the annual meeting of the Psychonomic Society, St. Louis, November 1976.

\section{REFERENCES}

Amble r, B. A., \& Proctor, J. D. The familiarity effect for single-letter pairs. Journal of Experimental Psychology: Human Perception and Performance, 1976, 2, 222-234. 
Appelman, I. B., \& Mayzner, M. S. The letter-frequency effect and the generality of familiarity effects on perception. Perception \& Psychophysics, 1981, 30, 436-446.

Briggs, G. E., \& Blaha, J. Memory retrieval and central comparison times in information processing. Journal of Experimental Psychology, 1969, 79, 395-402.

Carr, T. H., Lehmkuhle, S. W., Kottas, B., Astor-Stetson, E. C., \& ARNoLD, D. Target position and practice in the identification of letters in varying contexts: A word superiority effect. Perception \& Psychophysics, 1976, 19, 412-416.

Catrell, J. M. The time taken up by cerebral operations. Mind, 1886, 11, 220-242.

CoOper, L. A., \& Shepard, R. N. Chronometric studies of the rotation of mental images. In W. G. Chase (Ed.), Visual information processing. New York: Academic Press, 1973.

Dhewnowski, A., \& Healy, A. F. Detection errors on the and and: Evidence for reading units larger than the word. Memory \& Cognition, 1977, 5, 636-647.

Egeth, H., \& Blecker, D. Differential effects of familiarity on judgments of sameness and differences. Perception \& Psychophysics, 1971, 9, 321-326.

Fischler, I. Detection and identification of words and letters in simulated visual search of word lists. Memory \& Cognition, 1975, 3, 175-182.

HABER, R. N., \& Schindlen, R. M. Error in proofreading: Evidence of syntactic control of letter processing? Journal of Experimental Psychology: Human Perception and Performance, 1981, 7, 573-579.

Healy, A. F. Detection errors on the word the: Evidence for reading units larger than letters. Journal of Experimental Psychology: Human Perception and Performance, 1976, 2, 235-242.

Healy, A. F. Proofreading errors on the word the: New evidence on reading units. Journal of Experimental Psychology: Human Perception and Performance, 1980, 1, 45-57.

Hock, H. S. The effects of stimulus structure and familiarity on same-different comparison. Perception \& Psychophysics, 1973, $14,413-420$.

JAMEs, C. T. Vowels and consonants as targets in the search of single words. Bulletin of the Psychonomic Society, 1974, 2, 402-404.

JAmes, C. T., \& Smith, D. E. Sequential dependencies in letter search. Journal of Experimental Psychology, 1970, 85, 56-60.

Kaplan, I., \& Carvellas, T. Scanning for multiple targets. Perceptual and Motor Skills, 1965, 21, 239-241.

KEELE, S. W. Attention and human performance. Pacific Palisades, Calif: Goodyear, 1973.

Kolers, P. A., \& Perkins, D. N. Orientation of letters and their speed of recognition. Perception \& Psychophysics, 1969, $5,275-280$.

Kristofferson, M. W., Groen, M., \& Kristofferson, A. B. When visual search functions look like item recognition functions. Perception \& Psychophysics, 1973, 10, 386-392.

KRUEGer, L. E. Search time in a redundant visual display. Unpublished doctoral dissertation, Harvard University, 1969.

KRueger, L. E. Search time in a redundant visual display. Journal of Experimental Psychology, 1970, 83, 391-399. (a)

Krueaer, L. E. Visual comparison in a redundant display. Cognitive Psychology, 1970, 1, 341-357. (b)

KRUEOER, L. E. Familiarity effects in visual information processing. Psychological Bulletin, 1975, 82, 949-974.

KnUEaER, L. E. Evidence for directional scanning with the order- of-report factor excluded. Canadian Journal of Psychology, $1976,30,9-14$

KrUeger, L. E. A word-superiority effect with print and braille characters. Perception \& Psychophysics, 1982, 31, 345-352.

Krueger, L. E., KeEN, R. H., \& Rublevich, B. Letter search through words and nonwords by adults and fourth-grade children. Journal of Experimental Psychology, 1974, 102, 845849.

Krueger, L. E., \& Shapiro, R. G. Why search for target absence is so slow (and carefull): The more targets there are, the more likely you are to miss one. Journal of Experimental Psychology: Human Perception and Performance, 1980, 6, 662-685.

Krueger, L. E., \& Weiss, M. E. Letter search through words and nonwords: The effect of fixed, absent, or mutilated targets. Memory \& Cognition, 1976, 4, 200-206.

LAWRY, J. A. The interfering effect of word perception on letter identification. Perception \& Psychophysics, 1980, 28, 577-588.

Massaro, D. W. Primary and secondary recognition in reading. In D. W. Massaro (Ed.), Understanding language. New York: Academic Press, 1975.

McNeill, D., \& Lindia, $K$. The perceptual reality of phonemes, syllables, words and sentences. Journal of Verbal Learning and Verbal Behavior, 1973, 12, 419-430.

Moray, N. Where is capacity limited? A survey and a model. Acta Psychologica, 1967, 27, 84-92.

RAYNER, $K$. Foveal and parafoveal cues in reading. In J. Requin (Ed.), Attention and performance VIII. Hillsdale, N.J: Erlbaum, 1978.

REGAN, J. E. Effect of familiarity on multielement matching. Journal of Experimental Psychology: Human Perception and Performance, 1981, 7, 1273-1282.

Reicher, G. M. Perceptual recognition as a function of meaningfulness of stimulus material. Journal of Experimental Psychology, 1969, 81, 275-280.

Reicher, G. M., Snyder, C. R. R., \& Richards, J. T. Familiarity of background characters in visual scanning. Journal of Experimental Psychology: Human Perception and Performance, 1976, 2, 522-530.

SCHindeER, R. M. The effect of prose context on visual search for letters. Memory \& Cognition, 1978, 6, 124-130.

Sternbero, S. High-speed scanning in human memory. Science, $1966,153,652-654$.

Sternbero, S. Two operations in character recognition: Some evidence from reaction-time measurements. Perception \& Psy. chophysics, 1967, 2, 45-53.

Sternbero, S. The discovery of processing stages: Extensions of Donders' method. In W. G. Koster (Ed. \& trans.), Attention and performance II. Amsterdam: North-Holland, 1969. (Reprinted from Acta Psychologia, 1969, 30, 276-315.)

TAYLOR, R. L. Reading spatially transformed digits. Journal of Experimental Psychology, 1972, 96, 396-399.

Well, A. D., Pollatsex, A., \& Schindeer, R. M. Facilitation of both "same" and "different" judgments of letter strings by familiarity of letter sequence. Perception \& Psychophysics, 1975, 17, $511-520$.

WheEler, D. D. Processes in word recognition. Cognitive Psychology, 1970, 1, 59-85.

(Received for publication May 5, 1982; revision accepted September 17, 1982.) 